\title{
Post Combustion Behavior in In-bath Type Smelting Reduction Furnace
}

\author{
Kenji TAKAHASHI, Masahiro MUROYA, Kunihiro KONDO, Teruyuki HASEGAWA, Ichiro KIKUCHI' \\ and Masahiro KAWAKAMI ${ }^{2}$
}

Steel Research Center, NKK Corporation, Minamiwatarida-cho, Kawasaki-ku, Kawasaki, Kanagawa-ken, 210 Japan.

1) Steel Research Center, NKK Corporation, Kokan-cho, Fukuyama, Hiroshima-ken, 721 Japan.

2) Department of Steelmaking, Fukuyama Works, NKK Corporation, Kokan-cho, Fukuyama, Hiroshima-ken, 721 Japan.

(Received on June 26, 1991; accepted in final form on September 20, 1991)

In order to make a research on a new smelting reduction process, the iron bath based Smelting Reduction Furnace (SRF) with 5-ton iron bath capacity was installed in 1986 at NKK's Fukuyama Works and these test facilities were stepwisely built up.

In this paper, post combustion behavior in the SRF is described, based on the integrated operations with the SRF directly connected to the Pre-reduction Furnace (PRF).

Essential conditions to achieve high post combustion coupled with high heat transfer efficiency are summarized as follows;

1) Height adjustment of a top blowing lance according to the change of slag surface level, permitting post combustion within slag which is considered to be a major heat transfer medium,

2) Intensive agitation of slag phase by bottom blowing of gas,

3) Ultra soft blowing of oxygen through a double flow lance, and

4) Pressurized operation in which the depression of carry-over of charged coal is attainable.

Under these conditions, longterm continuous operations over $10 \mathrm{~h}$ were stably carried out at high level of post combustion of $50 \%$ with heat transfer efficiency of more than $85 \%$ even in the use of high volatile coals.

In the tests using various carbonaceous materials such as coke, medium volatile coal and high volatile coals, effects of volatile matter on post combustion were investigated.

Furthermore, modelling of post combustion was studied to optimize the operating conditions in a larger scale furnace.

KEY WORDS: iron making; steel making; post combustion; smelting reduction; pre-reduction; fluidized bed; in-bath smelting reduction; heat transfer; iron ore; coke; coal; sinter; volatile matter

\section{Introduction}

In NKK, R \& D activities of smelting reduction process were started in 1978. And the concept of a new process which should be an alternative to the current iron making blast furnace process was postulated by 1984 . It consists of an iron bath based Smelting Reduction Furnace (SRF) linked to a Pre-reduction Furnace (PRF), which should contain some features as follows;

1) Extended flexibility of selection of resources by the ability to directly use raw materials such as noncoking coals and ores,

2) Cost reduction of the capital investment and operation because of the elimination of sinter, pellet and coke plants,

3) Easy adjustment of production rate of hot metal by the quick start/stop of the operation, and

4) Adequate control of sensible and chemical heat in the exhaust gas which may comply with the energy requirements at the steelworks.
In order to realize this new process, it is important to develop the following technologies:

- Post combustion at high level coupled with high heat transfer efficiency for thermal compensation of iron ore reduction in the SRF.

- Direct use of the offgas from the SRF for the prereduction of iron ore in the PRF.

- Stable operation of these two furnaces.

It had been considered that high post combustion degree of more than $50 \%$ is unattainable in the state of high heat transfer efficiency in the BOF process. In 1985, fundamental studies were therefore conducted in a laboratory scale for the purpose of making clear the necessary conditions to improve post combustion in the SRF. ${ }^{1-2)}$ Based on the results of fundamental studies, the SRF with 5-ton iron bath capacity was installed at Fukuyama Works and the operations were commenced in September, 1986.

The conditions for improving thermal efficiency of post combustion in the SRF were obtained through the 
fundamental studies and operations of the 5-ton scale SRF. ${ }^{3-4)}$ Then, in April of 1988, the PRF was installed at the upper space above the SRF and these two furnaces were connected through offgas ducts. Hence the integrated operations have been carried out. ${ }^{5-7)}$ Further in March of 1989, for the purpose of longterm continuous operations, the equipment for tapping was attached to the SRF.

Since October of 1988 the subject tests have been conducted as part of the joint research in accordance with the development activities in the Japanese National Project, Direct Iron Ore Smelting Reduction Process (DIOS). These results are described in previous publications. ${ }^{8-11)}$

In this paper, post combustion and influence of factors on its behavior in the in-bath type SRF are described from results of the above-mentioned research of NKK's own as well as the joint research.

\section{Concept of New Smelting Reduction Process}

The smelting reduction processes have been actively investigated ${ }^{12-14)}$ as an innovative iron making and NKK has been aiming at the process to become an alternative to the blast furnace process. The new process should be furnished with the positive features of the blast furnace process, which are high energy efficiency, high productivity and energy supply equivalent to meet the requirements of other plants at the integrated steelworks. Furthermore, the new process should have other features that will eliminate the weak points of the blast furnace process in order to pursue better cost reduction. Those requirements can be satisfied by the use of the in-bath type SRF where iron ore is reduced rapidly and no special preparation for coal and iron ore is necessary. The PRF is also useful in minimizing the total energy consumption by utilizing the offgas from the SRF.

At various pre-reduction degrees of iron ore (PRD), Fig. 1 shows the influence of post combustion degree on coal consumption per ton hot metal produced and surplus energy evolved from the smelting reduction process. Post combustion degree here is represented as oxidation degree of offgas (OD) which is given off from the SRF.

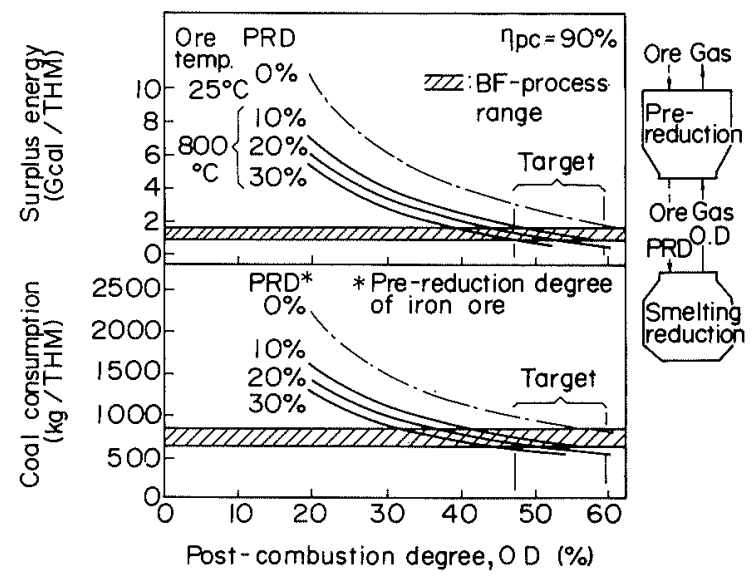

Fig. 1. Effect of post combustion degree in smelting reduction furnace on coal consumption rate and surplus energy evolved from the process.
And OD is calculated from the composition of the offgas by Eq. (1);

$$
\mathrm{OD}=\frac{\mathrm{CO}_{2}+\mathrm{H}_{2} \mathrm{O}}{\mathrm{CO}+\mathrm{CO}_{2}+\mathrm{H}_{2}+\mathrm{H}_{2} \mathrm{O}} \times 100(\%)
$$

If higher OD than $50 \%$ is obtained, lower coal consumption can be obtained than that for blast furnace process with the equivalent surplus energy, even if PRD is lower than $30 \%$.

The combination of low OD $(<50 \%)$ and high PRD $(>30 \%)$ yields unnecessary excess process gas energy, more than that required at the integrated steelworks. When higher PRD than $30 \%$ is desired, OD should be kept lower than $30 \%$ to secure reduction potential for the pre-reduction. This gives a substantial increase of required process gas for the PRF, much larger than the energy required in the subsequent plants.

Therefore, the combination of intensive post combustion $(\mathrm{OD} \geqq 50 \%)$ and the light pre-reduction is considered to be reasonable as the alternative process.

\section{Test Facilities and Procedure}

\subsection{Test Facilities}

Figure 2 represents a flowsheet of Fukuyama's smelting reduction test facilities and the principal specifications of the PRF and the SRF are described in Table 1.

Iron ore is pre-heated and pre-reduced in the PRF by the offgas evolved from the SRF. It is classified into coarse and fine grains and charged into the SRF respectively through $\underline{\text { Hot }}$ Ore Charging Tanks $(\mathrm{H}-\mathrm{OCT})$ and $\underline{H}$ ot Ore Injection Tanks (H-OIT).

Since the addition of the tapping equipment in the SRF, the discharge of hot metal and slag has been carried out at an interval of about $90 \mathrm{~min}$ without tilting the

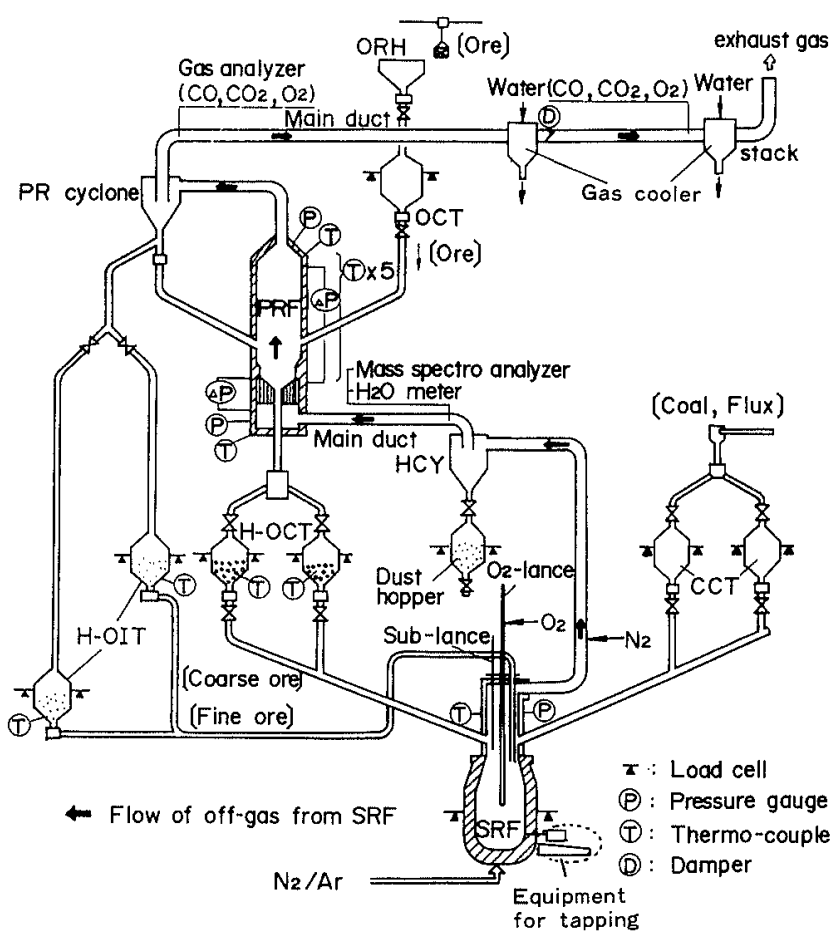

Fig. 2. Flowsheet of smelting reduction test plant at Fukuyama. 
SRF.

In the followings are described the principal features of the test facilities;

(1) The basic structure of the SRF is the same as that of the BOF with top and bottom blowing of gas. Oxygen is top blown through a double flow lance, which is specially designed so that high post combustion is attainable. Bottom blowing of inert gas for bath agitation can be done with a wide flow rate range.

As the SRF refractories, magnesite-chrome bricks are used. Also, in order to minimize heat loss, thermal insulation bricks are set between the magnesite-chrome bricks and the shell of the furnace.

(2) The type of the PRF is a fluidized bed and it is possible to use sinter feed ore having a fairly wide range of grain size (5 mm or less in particle diameter).

(3) In order to introduce the offgas from the SRF to the PRF and to stably form a fluidized bed, the SRF is operated under the pressurized condition of more than $0.7 \mathrm{kgf} / \mathrm{cm}^{2} \mathrm{G}$. The dusty offgas of the SRF is cleaned by the Hot Cyclone (HCY) and then introduced to the PRF.

(4) It is possible to obtain accurate online information on material- and heat-balance with the aid of the mass spectroanalyser and of the precise weighing of various material flows including the exhausted dust. The accuracy of the gas analysis is guaranteed by the complete

Table 1. Specifications of the PRF and SRF.

\begin{tabular}{llll}
\hline \multirow{4}{*}{ PRF } & (1) Type & (2) Capacity & $:$ Bubbling bed \\
& (3) Gas flow rate & $: 4000-8000 \mathrm{Nm}^{3} / \mathrm{h}$ \\
& (4) Iron ore & $:$ Sinter feed $(-5 \mathrm{~mm})$ \\
\hline \multirow{3}{*}{ SRF } & (1) Type & $:$ In-bath smelting reduction furnace \\
& (2) Inner volume & $: 7 \mathrm{~m}^{3}$ as lined \\
& (3) Oxygen flow rate: $\sim 2500 \mathrm{Nm}^{3} / \mathrm{h}$ \\
\hline
\end{tabular}

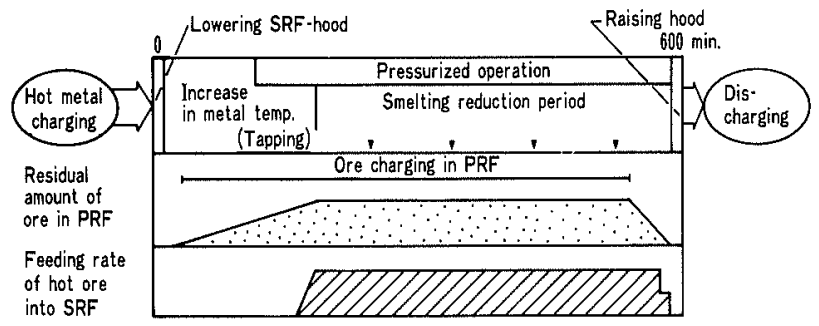

Fig. 3. Operational procedure of the smelting reduction test. closing of the system from the atmosphere.

\subsection{Test Procedure}

In Fig. 3 is shown an operational procedure of the smelting reduction test, which is the same that previously reported. ${ }^{12)}$ After the tapping equipment was installed in March, 1989, longterm continuous operations over $10 \mathrm{~h}$ have been carried out.

In Table 2, chemical compositions of the iron ore and carbonaceous materials used in the tests are shown. As for carbonaceous materials, High Volatile coal 1 and 2 (HV1, HV2 coals) were mainly used. Additionally, in order to investigate the effects of volatile matter on post combustion, Medium Volatile coal (MV coal) and coke were also used.

\section{Test Results and Discussion}

\subsection{SRF Operation under High Post Combustion}

Figure 4 shows the changes of principal operational particulars in the case of a 10 -h continuous operation using HV1 coal. During the smelting reduction period including the tapping,

1) high post combustion was stably achieved by maintaining high flow rate of oxygen, and

2) smooth introduction of the offgas from the SRF to the PRF permitted the formation of the stable fluidized bed in the PRF.

\subsection{Post Combustion in the SRF}

\subsubsection{Primary Conditions for Post Combustion}

In top and bottom blowing converters, trials to obtain high level of post combustion were undertaken, for example, by making the position of an oxygen lance higher. ${ }^{13,14)}$ In such cases, the heat transfer efficiency was kept high within the range of low OD. However, with an increase in $O D$, the heat transfer efficiency decreased.

In the SRF, the heat transfer efficiency $\left(\eta_{\mathrm{PC}}\right)$ is defined as shown in Appendix 1.

In order to obtain low coal consumption, it is important to achieve simultaneously high OD and high $\eta_{\mathrm{PC}}$. Also, an increase of $\eta_{\mathrm{PC}}$ results in lowering offgas temperature after post combustion, which may prevent the refractory damage. Figure $\mathbf{5}$ shows the primary conditions for efficient post combustion in the SRF. Details are described in previous report. ${ }^{12)}$

When the heat of post combustion is transferred from

Table 2. Chemical compositions of materials used

$(w t \%)$

\begin{tabular}{|c|c|c|c|c|c|c|c|c|}
\hline \multirow[t]{2}{*}{ Ore } & $\begin{array}{l}\text { T.Fe } \\
68.8\end{array}$ & \multicolumn{2}{|c|}{$\begin{array}{c}\mathrm{FeO} \\
2.8\end{array}$} & $\begin{array}{l}\mathrm{SiO}_{2} \\
0.73\end{array}$ & $\begin{array}{c}\mathrm{Al}_{2} \mathrm{O}_{3} \\
0.78\end{array}$ & \multicolumn{2}{|c|}{$\begin{array}{l}\mathrm{CaO} \\
0.16\end{array}$} & \multirow{2}{*}{$\begin{array}{l}\mathrm{MgO} \\
0.03 \\
\text { (dry base) }\end{array}$} \\
\hline & & & & & & & & \\
\hline \multirow{2}{*}{$\begin{array}{c}\text { Carbonaceous } \\
\text { materials }\end{array}$} & \multicolumn{3}{|c|}{ Proximate analysis } & \multicolumn{5}{|c|}{ Ultimate analysis } \\
\hline & Ash & $\mathrm{VM}$ & F.C & $\mathrm{C}$ & $\mathrm{H}$ & $\mathbf{N}$ & $\mathrm{O}$ & $\mathrm{S}$ \\
\hline HV1 & 10.4 & 31.7 & 57.9 & 73.3 & 4.6 & 1.7 & 9.5 & 0.5 \\
\hline HV2 & 9.2 & 36.6 & 54.2 & 74.2 & 5.2 & 1.6 & 9.3 & 0.5 \\
\hline MV & 12.3 & 22.0 & 65.7 & 77.7 & 5.4 & 1.4 & 2.9 & 0.3 \\
\hline Coke & 12.9 & 0.5 & 86.6 & 85.4 & 0.4 & 0.9 & 0.2 & 0.2 \\
\hline
\end{tabular}




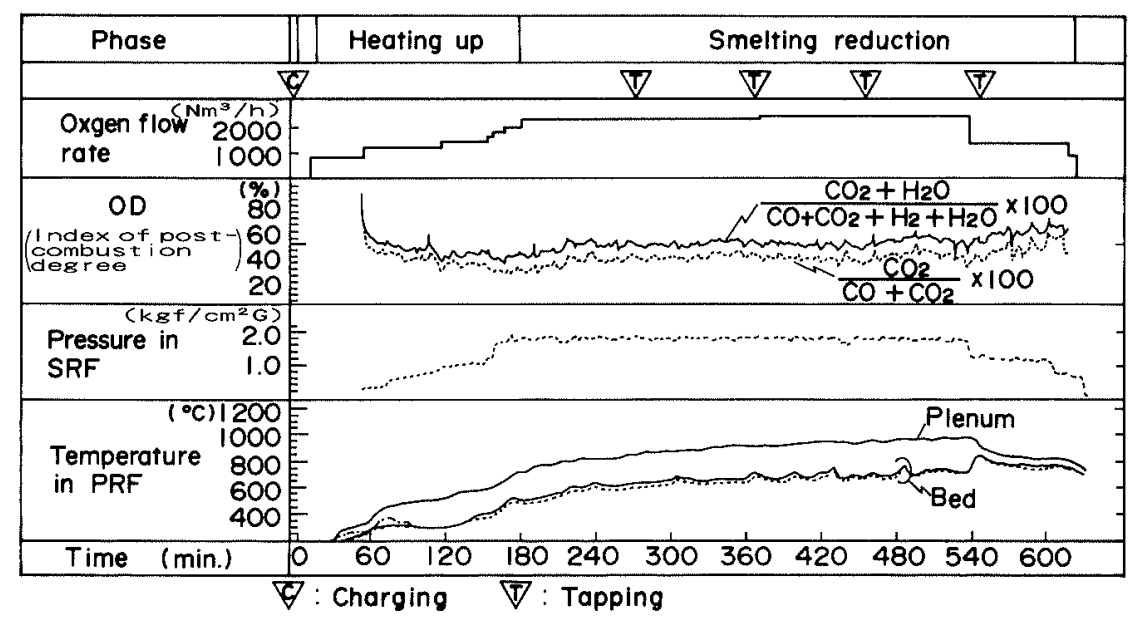

Fig. 4. Example of the SRF-PRF integrated operation.

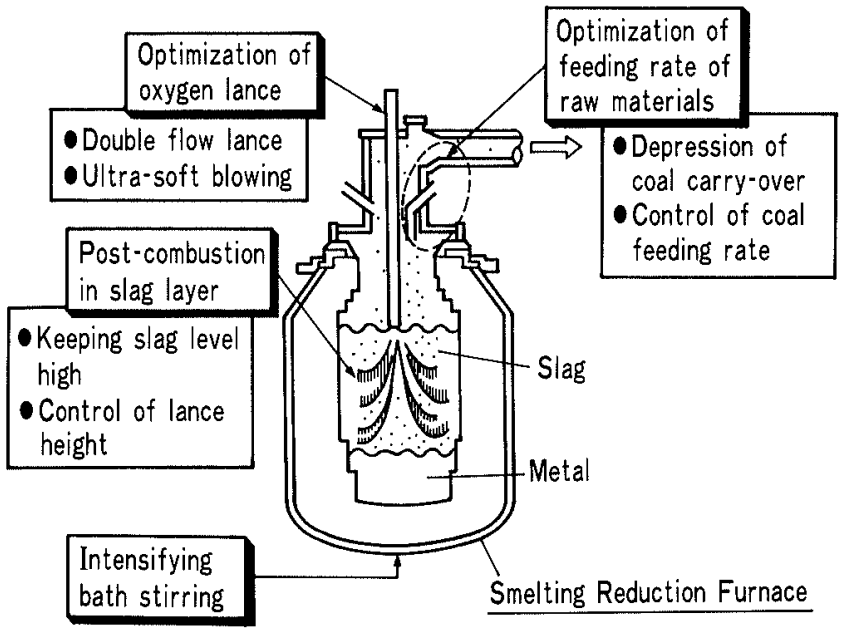

Fig. 5. Key factors to achieve efficient post combustion in the SRF.

the high temperature gas to the iron bath, it is considered that slag may play an important role as heat transfer medium. From this reason, key aspects of the SRF operation are as follows;

(1) In order to maintain high $\eta_{\mathrm{PC}}$, it is important to properly control the distance between the tip of the oxygen lance and the slag surface so that post combustion may be carried out within the slag. Also, for the purpose of eliminating uneven temperature distribution in slag and accelerating the heat transfer from the post combustion zone to the bath, the bath should be intensively agitated by bottom blowing gas.

(2) In order to obtain high $\mathrm{OD}$,

i) the oxygen lance should have a multihole structure, which may permit a called "ultra soft blow operation". This lance can restrain the reaction between oxygen and $[\mathrm{C}]$ in metal bath or droplets and secure the sufficient mixing with oxygen gas and $\mathrm{CO}$ gas generated in the SRF, and

ii) it is necessary to properly control the oxygen flow rate and feeding rate of iron ore and carbonaceous materials, based on the heat- and materialbalances which should be suitable for high OD.

Taking account of these key aspects, the SRF op-

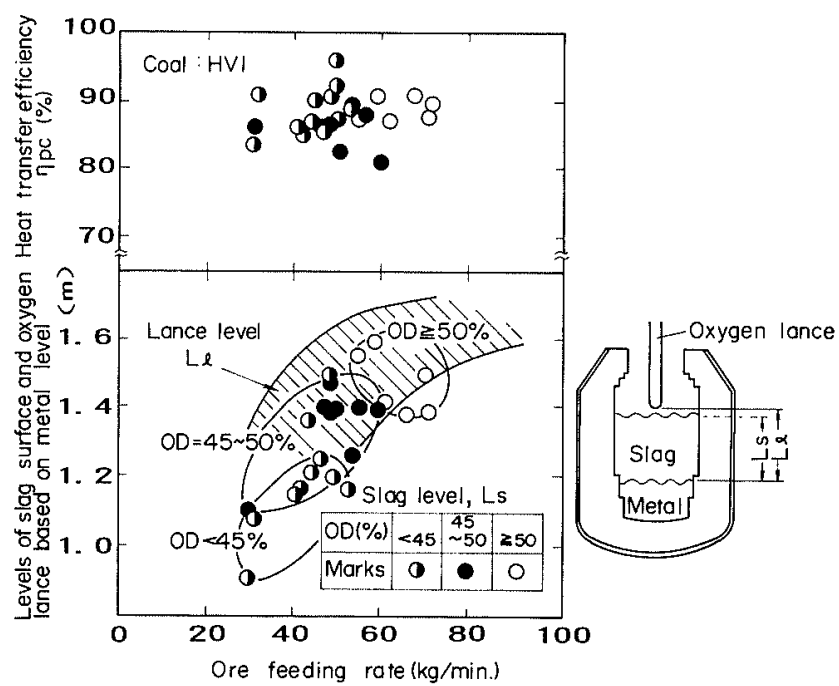

Fig. 6. Relationship between the iron ore feeding rate, slag surface level and $\eta_{\mathrm{PC}}$ with a parameter of $\mathrm{OD}$.

erations were conducted. Figure 6 shows the relationship between the ore feeding rates and the slag surface level with a parameter of OD. The lance level and obtained $\eta_{\text {PC }}$ are also shown.

With an increase in the ore feeding rate, the slag level becomes stabilized at higher position. By raising the lance according to the change of the slag surface level, the post combustion and heat transfer zone may be widely formed inside the slag. Consequently, high OD and high $\eta_{\mathrm{PC}}$ are simultaneously obtained.

\subsubsection{Influences of Carbonaceous Materials on Post Combustion}

(1) Consumption of Carbonaceous Materials and Heat/Carbon Balance

Figure 7 shows the relationship between OD and $\eta_{\mathrm{PC}}$ using various kinds of carbonaceous materials. The levels of $\eta_{\mathrm{PC}}$ are kept over $85 \%$ in every kind and as for OD,
Coke:
$60-70 \%$
MV coal: $\quad 55-60 \%$
HV coal: ca. $50 \%$

are obtained.

Consumptions of carbonaceous materials per ton hot metal produced are shown in Fig. 8 as a function of 
production rate. This figure demonstrates that the increase in the production rate and in OD level lowers the consumption of carbonaceous material. On comparison at the same production rate, higher OD can be easily

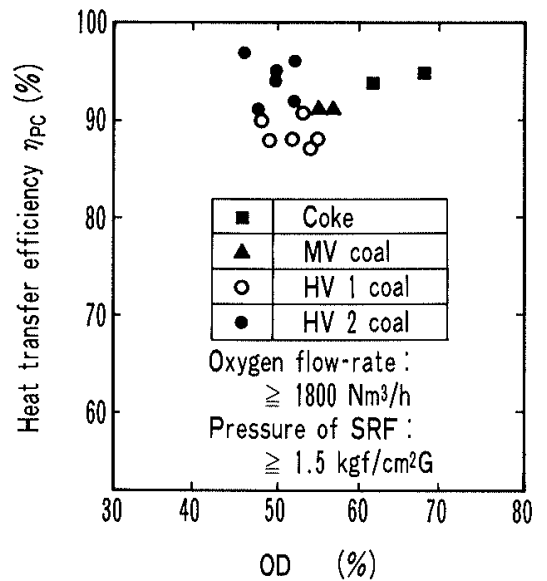

Fig. 7. Relationship between $\mathrm{OD}$ and $\eta_{\mathrm{PC}}$ in various carbonaceous materials. obtained in the case of coke and MV coal, resulting in low consumption.

Figure 9 shows examples of heat and carbon balances at the same production rate of hot metal in the use of HV2 coal and coke. Both results show the high $\eta_{\mathbf{P C}}$ of $95 \%$. In the operation using HV2 coal, to compensate

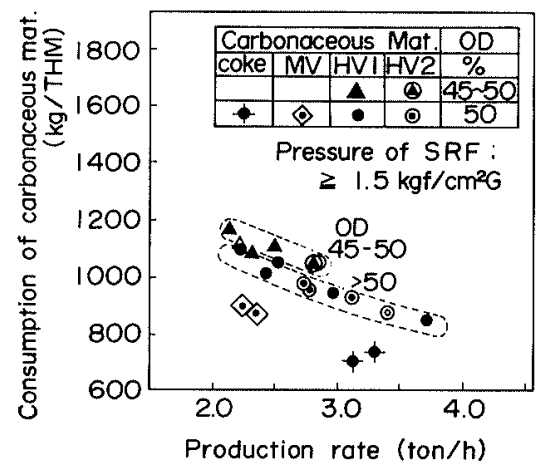

Fig. 8. Consumption of carbonaceous materials as a function of production rate.

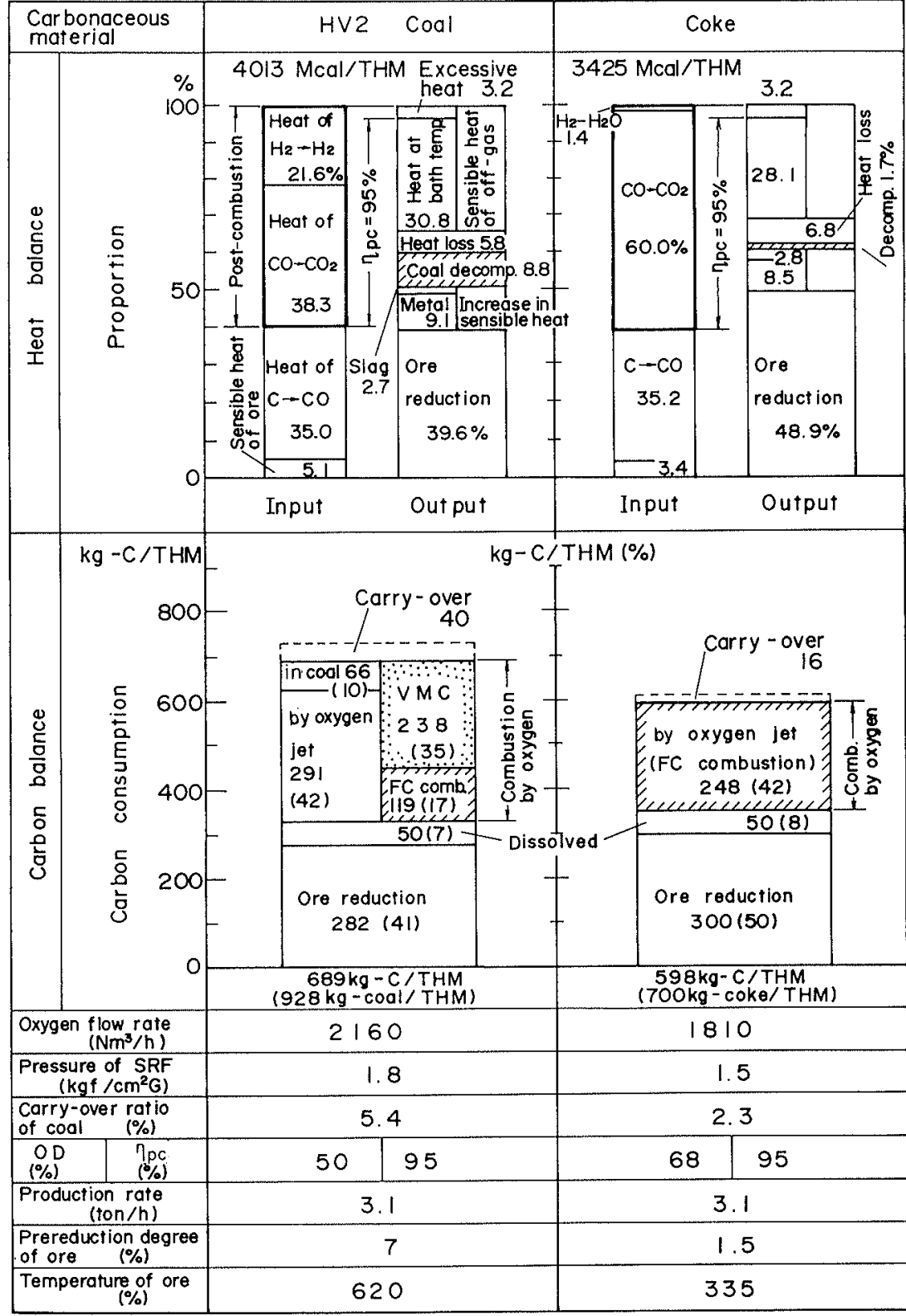

Fig. 9.

Example of heat and carbon balances 


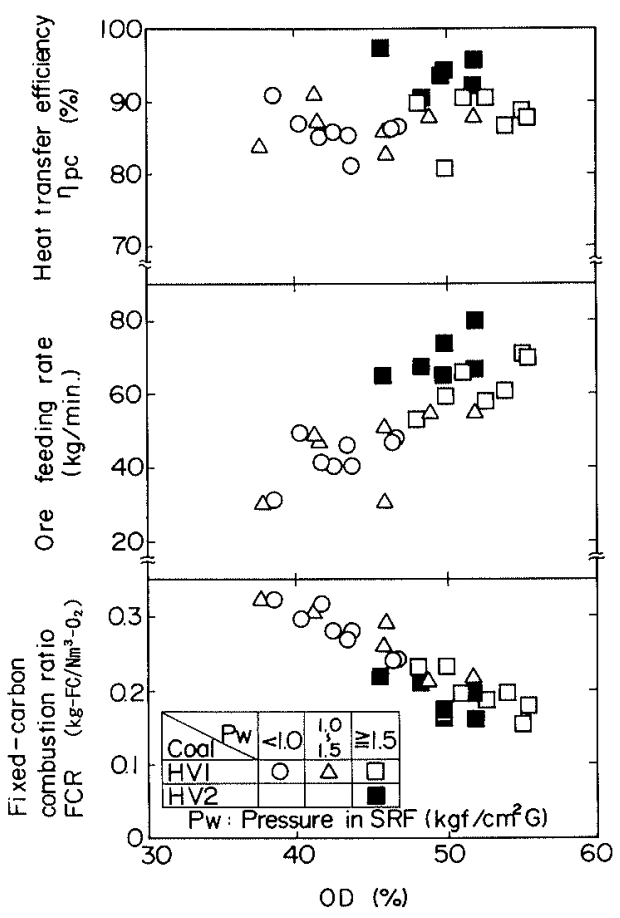

Fig. 10. Behavior of $\mathrm{OD}$ and $\eta_{\mathrm{PC}}$ and its influence on fixed carbon combustion ratio.

the decomposition heat of the coal and sensible heat of gas taken away by devolatilization, the amount of heat required becomes larger than that in the operation using coke.

Carbon in HV2 coal or coke is consumed by the reduction, dissolution into metal produced and combustion. The amount of combustion of fixed carbon in coal or coke is expressed as Fixed Carbon (FC) combustion.

In the case of $\mathrm{HV} 2$ coal, carbon of volatile matter besides the FC is consumed by combustion. When the carbon content of volatile matter was measured in the high temperature field over $1200^{\circ} \mathrm{C}$, it was higher than that obtained in the proximate analysis. ${ }^{15)}$ As described in Appendix 2.1, the content of carbon directly gasified was estimated in each carbonaceous material and defined as VMC. In the operation using HV coal, higher OD achieved by the efficient combustion of the VMC as well as $\mathrm{CO}$ gas may lead to the lower coal consumption.

\section{(2) Fixed Carbon Combustion}

The operation at high level of post combustion means achieving efficient combustion of carbon and hydrogen of volatile matter by the adequate operational control. Thereby, the amount of FC combustion may be decreased.

To clarify the relationship between the amount of FC combustion and the oxygen flow rate, Fixed Carbon Combustion Ratio (FCR) is defined as written in Appendix 2.2. Figure 10 shows the influence of OD on the FCR, the feeding rate of iron ore and $\eta_{\mathrm{PC}}$ as a parameter of the pressure in the SRF. By raising the operation pressure of the SRF, OD becomes higher in the state that $\eta_{\mathrm{PC}}$ is kept at high level of more than $80 \%$. It permits an increase in the feeding rate of iron ore. Consequently, the slag layer is sufficiently formed to enhance post combustion and FCR becomes smaller.

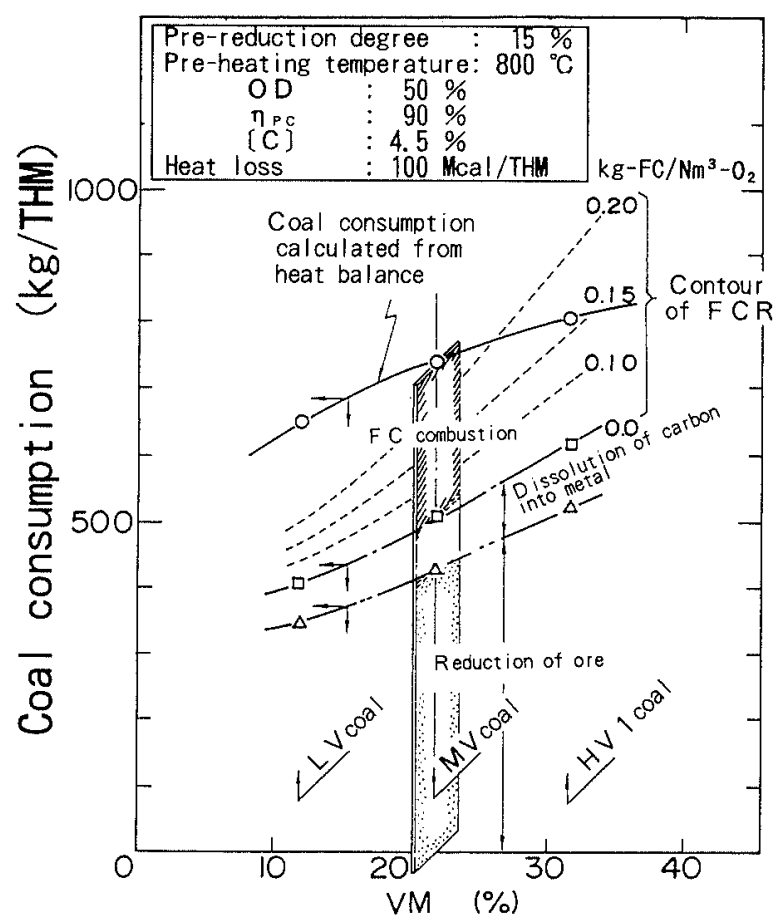

Fig. 11. Influence of volatile matter on coal consumption.

Figure 11 shows the relationship between VM and coal consumption calculated from heat balance. The main conditions of calculation are written in the figure. Also, it is assumed that the smelting reduction and the carbon dissolution occur by FC in coal. In each kind of coals - Low Volatile coal (LV coal, MV: $11.8 \%$, F.C.: $79.6 \%$ ), MV coal and HV1 coal (their chemical compositions are shown in Table 2)-,

1) the amount of coal consumed by smelting reduction of iron ore [ $\triangle$ in the figure],

2) the amount which is obtained by adding the coal amount consumed by carbon dissolution to 1) [ditto $\square]$, and

3) the amount of coal which is obtained by adding coal amount required for compensating heat in shortage to 2) [ditto $O$; total coal consumption per ton hot metal produced]

are plotted. In addition, contours of FCR are also drawn by broken lines.

An increase in VM of coal raises essentially coal consumption. However, in every coal, lower coal consumption can be obtained by lowering FCR which results from high $\mathrm{OD}$ coupled with high $\eta_{\mathrm{PC}}$. Under conditions shown in Fig. 11, for example, the consumption of HV1 coal should be about $820 \mathrm{~kg} / \mathrm{THM}$ at FCR of about $0.16 \mathrm{~kg}-\mathrm{FC} / \mathrm{Nm}^{3}-\mathrm{O}_{2}$.

\subsubsection{Coal Carry-over}

As described in the above, in order to keep stable and high post combustion operation of the SRF, it is necessary to adequately control the ratios of carbon to oxygen charged. Especially, because the behavior of coal charged in the SRF influences the post combustion to a great degree, it is essential to grasp and depress the amount of coal carried-over during the operation.

Figure 12 shows the change of the operation pressure of the SRF and its results. By increasing the pressure, 


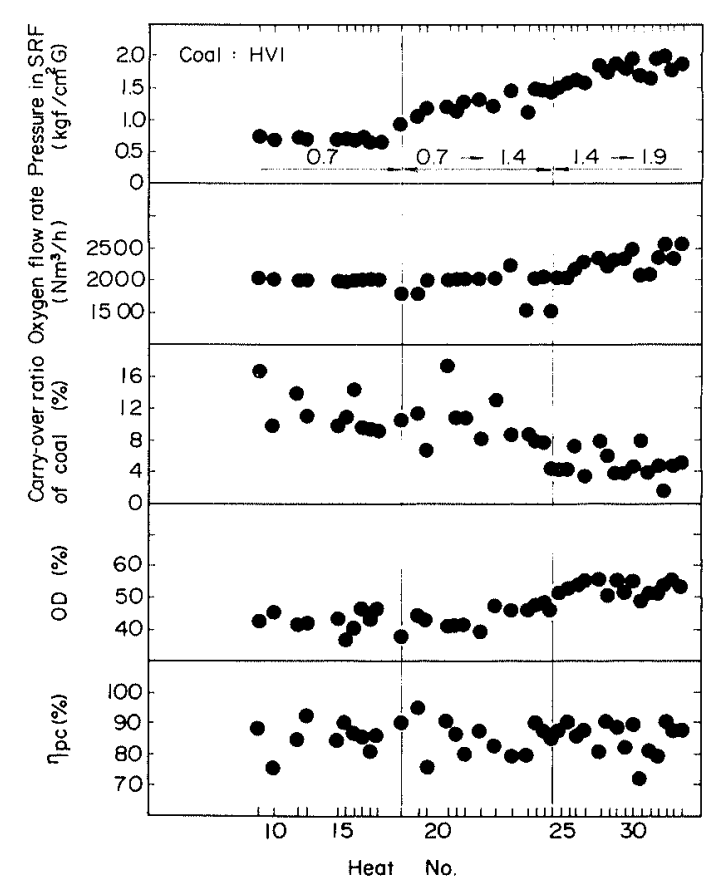

Fig. 12. Influence of the pressure of the SRF on the coal carry-over and $O D$

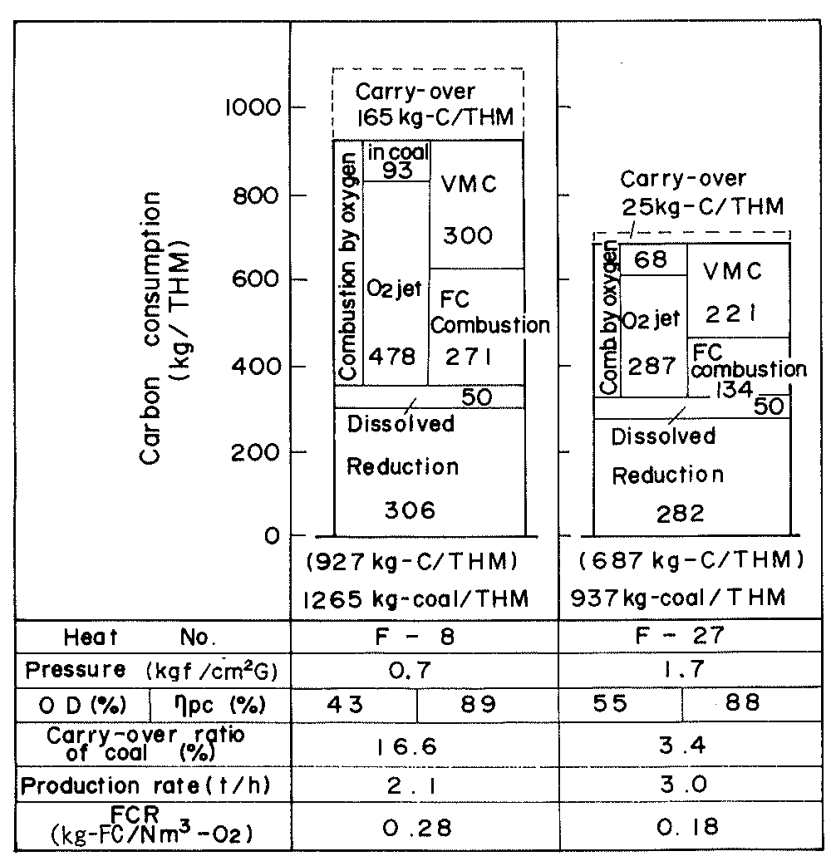

Fig. 13. Carbon balance in smelting reduction using HVI coal.

coal carry-over ratio (\{carbon amount in dust generated $\} /$ \{carbon amount charged\} $\times 100 \%$ ) was decreased. This enabled the stable operation at high flow rate of oxygen, and OD was increasing up to $50 \%$ or more while $\eta_{\mathrm{PC}}$ was kept high.

In the tests carried out at Fukuyama, the operation pressure of the SRF was initially $0.7 \mathrm{kgf} / \mathrm{cm}^{2} \mathrm{G}$. Since favorable effect of raising the pressure on $O D$ was confirmed ${ }^{8,9)}$ the standard pressure has been increased up to about $1.8 \mathrm{kgf} / \mathrm{cm}^{2} \mathrm{G}$.

Figure 13 shows examples of carbon balance in low pressure (Heat No. F-8) and high pressure (ditto F-27)

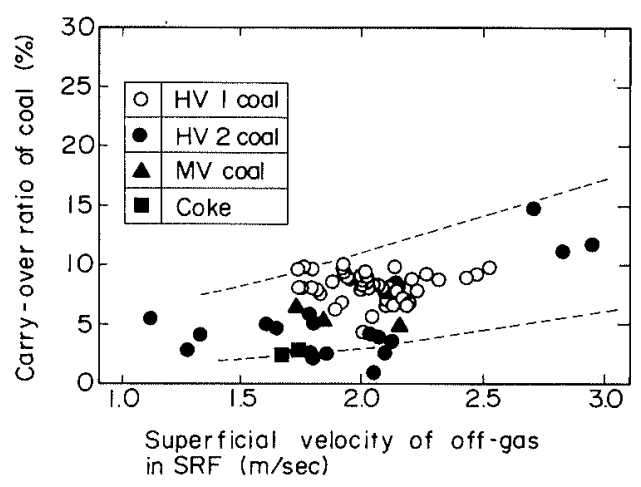

Fig. 14. Influence of superficial velocity of offgas in the SRF on coal carry-over.

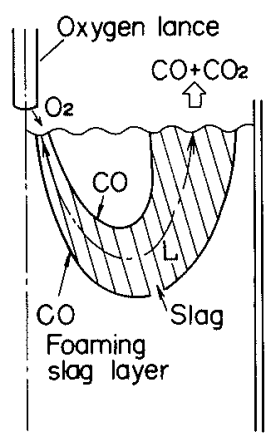

Fig. 15. Concept of heat transfer in post combustion of the SRF.

operations using HVl coal. By raising the pressure from 0.7 to $1.7 \mathrm{kgf} / \mathrm{cm}^{2} \mathrm{G}$, coal carry-over ratio is considerably depressed and higher OD is obtained with high $\eta_{\mathrm{PC}}$. Consequently, the lower consumption of coal is achieved with a decrease in the FCR.

Figure 14 shows the relationship between carry-over ratios of several kinds of carbonaceous materials and superficial velocities of the offgas within the SRF. By lowering the superficial velocity, the carry-over ratio is decreasing. This is one of effects of the pressurized operation in the SRF.

\subsection{Modelling of Post Combustion Behavior}

In order to obtain a suitable index for oxygen nozzle designs and operations, modelling of post combustion was carried out. ${ }^{16,17)}$

The post combustion zone is assumed to be within slag as shown in Fig. 15, where slag may play an important role as heat transfer medium. Oxygen blown into slag reacts with $\mathrm{CO}$ gas generated within the furnace. The heat of the reaction is transferred to slag. In the figure, the shaded area corresponds to the zone of the post combustion and heat transfer between combustion gas and slag. From the heat balance between gas and slag in a minute field of one dimensional flow and the experimental data, $\eta_{\mathrm{PC}}$ is described by Eq. (2);

$$
\eta_{\mathrm{PC}}=100-90 \cdot(\mathrm{OD} / 100)^{0.9} \cdot P^{-1}
$$

where, $P=350 \cdot n \cdot L / V_{g}$

$n$ : number of nozzles

$L$ : length of post combustion, which is obtained by the modified equation by 


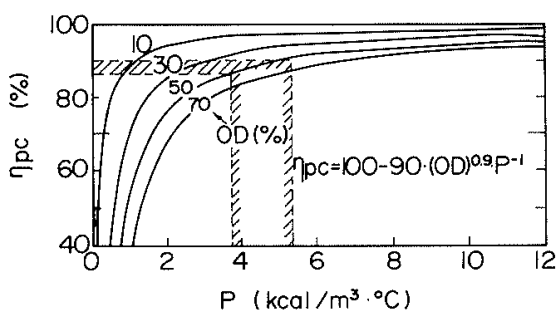

Fig. 16. Influence of parameter, $P$-value, on heat transfer efficiency, $\eta_{\mathrm{PC}}$ as a function of $\mathrm{OD}$

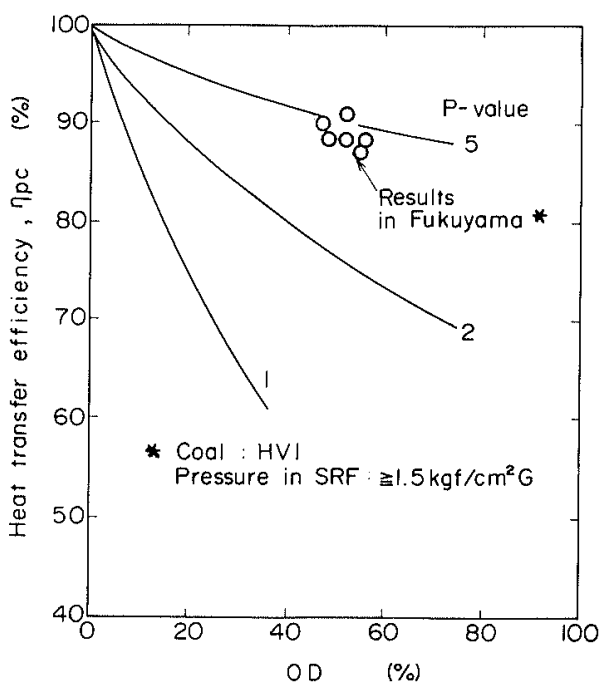

Fig. 17. Estimation of $P$-value in Fukuyama's results.

Engh et al. ${ }^{18)}$

$V_{g}$ : gas superficial velocity.

$P$-value is an operational index representing heat transfer efficiency. The relationship between the $P$-value and $\eta_{\mathrm{PC}}$ is illustrated with a parameter OD in Fig. 16. For example, in the case of $\mathrm{OD}=50 \%$, the $P$-values corresponding to $\eta_{\mathrm{PC}}=85-90 \%$ exist in the hatched region.

Figure 17 shows the results of the SRF operation at Fukuyama Works. By increasing $P$-value by means of the lance with multiple holes, high $\eta_{\mathrm{PC}}(90 \%)$ is obtained when $\mathrm{OD}=50 \%$.

For the purpose of high OD and high $\eta_{\mathrm{PC}}$, it is important to uniformly cover the bath surface with oxygen jet and to secure the heat transfer area from high temperature gas to slag. On this assumption, it is considered to be possible to study oxygen blowing conditions such as nozzle designs in a larger scale SRF by the $P$-value.

\section{Conclusion}

In the integrated operations with the Smelting Reduction Furnace (SRF) with 5-ton iron bath capacity directly connected to the Pre-reduction Furnace (PRF) at Fukuyama Works, the following knowledges relating to post combustion behavior in the SRF have been obtained;

(1) Basic conditions to achieve simultaneously high post combustion degree and high heat transfer efficiency are,
(1) the combustion inside slag to utilize slag as heat transfer medium and the intensified agitation of bath by bottom blowing of gas to accelerate heat transfer,

(2) the adequate design of top-blowing oxygen lance to restrain the reaction of oxygen with $[\mathrm{C}]$ in metal bath or droplets, and

(3) control of carbon/oxygen balance in the SRF.

(2) It has been clarified that high post combustion degree and high heat transfer efficiency are obtained through the depression of coal carry-over in the pressurized operation. This results in the increase of feeding rate of iron ore and in the formation of efficient post combustion/heat transfer zone.

(3) Heat and carbon balances under high post combustion and high heat transfer efficiency have been clarified in the use of coke, MV coal and HV coal. Volatile matter influences post combustion greatly.

(4) Modelling of post combustion was studied, and the $P$-value was obtained as an index for heat transfer efficiency.

\section{REFERENCES}

1) H. Nakamura, K. Takahashi, Y. Kawai, S. Sugiyama, M. Abe and A. Ozeki: Tetsu-to-Hagané, 72 (1986), S182.

2) S. Nishioka, K. Takahashi, H. Nakamura, Y. Kawai and S. Sugiyama: Tetsu-to-Hagané, 72 (1986), S1030.

3) H. Kawata, H. Tanabe, M. Kawakami, K. Kondo, M. Nishi and G. Kanatani: CAMP-ISIJ, I (1988), 1084.

4) K. Iwasaki, K. Takahashi, I. Kikuchi, K. Yamada, S. Nishioka and T. Kitagawa: CAMP-ISIJ, 1 (1988), 1085.

5) M. Kawakami, H. Kawata, H. Tanabe, K. Takahashi, G. Kanatani and M. Matsuo: CAMP-ISIJ, 2 (1989), 167.

6) M. Kawakami, H. Kawata, H. Tanabe, M. Muroya, K. Takahashi and T. Kitagawa: CAMP-ISIJ, 2 (1989), 168.

7) I. Kikuchi, K. Iwasaki, M. Muroya, K. Takahashi, K. Yamada and T. Kitagawa: CAMP-ISIJ, 2 (1989), 169.

8) H. Kawata, M. Kawakami, T. Ariyama, H. Tanabe, K. Takahashi, T. Kitagawa and Y. Kamei: CAMP-ISIJ, 3 (1990), 1071 .

9) K. Iwasaki, I. Kikuchi, S. Nishioka, K. Kondo, K. Takahashi and K. Yamada: CAMP-ISIJ, 3 (1990), 1072.

10) M. Kawakami, I. Kikuchi, H. Kawata, K. Takahashi, H. Kawata, T. Kitagawa and T. Inatani: CAMP-ISIJ, 4 (1991), 45.

11) I. Kikuchi, M. Kawakami, M. Muroya, K. Takahashi and T. Kitagawa: CAMP-ISIJ, 4 (1991), 46.

12) K. Takahashi, H. Tanabe, K. Iwasaki, M. Muroya, I. Kikuchi and M. Kawakami: Tetsu-to-Hagané, 76 (1990), 1887.

13) H. Okuda, H. Take, T. Yamada and E. Fritz: Tetsu-to-Hagané, 71 (1985), S186.

14) T. Saito, Y. Nakamura, H. Ishikawa, S. Yamamoto, K. Baba and Y. Kyojima: Tetsu-to-Hagané, 70 (1984), S1030.

15) Y. Suzuki, S. Itagaki, N. Mitani, H. Yanaka, S. Nishioka and M. Muroya: CAMP-ISIJ, 2 (1989), 1047.

16) S. Sugiyama, M. Abe, S. Nishioka, H. Nakamura, K. Takahashi and Y. Kawai: Tetsu-lo-Hagané, 72 (1986), S1029.

17) S. Nishioka, H. Nakamura, Y. Kawai and S. Sugiyama: Tetsu-to-Hagane, 76 (1990), 2019.

18) T. A. Engh and H. Bertheussen: Scand. J. Metall., 4 (1975), 241 .

\section{Appendix 1}

Heat transfer efficiency, $\eta_{\mathrm{PC}}$, is defined as follows;

$\eta_{\mathrm{PC}}=1-\left\{\frac{(\text { Amount of superheat of offgas })}{\left(\begin{array}{c}\text { Amount of reaction heat } \\ \text { generated by post combustion }\end{array}\right)}\right\} \times 100(\%)$ 


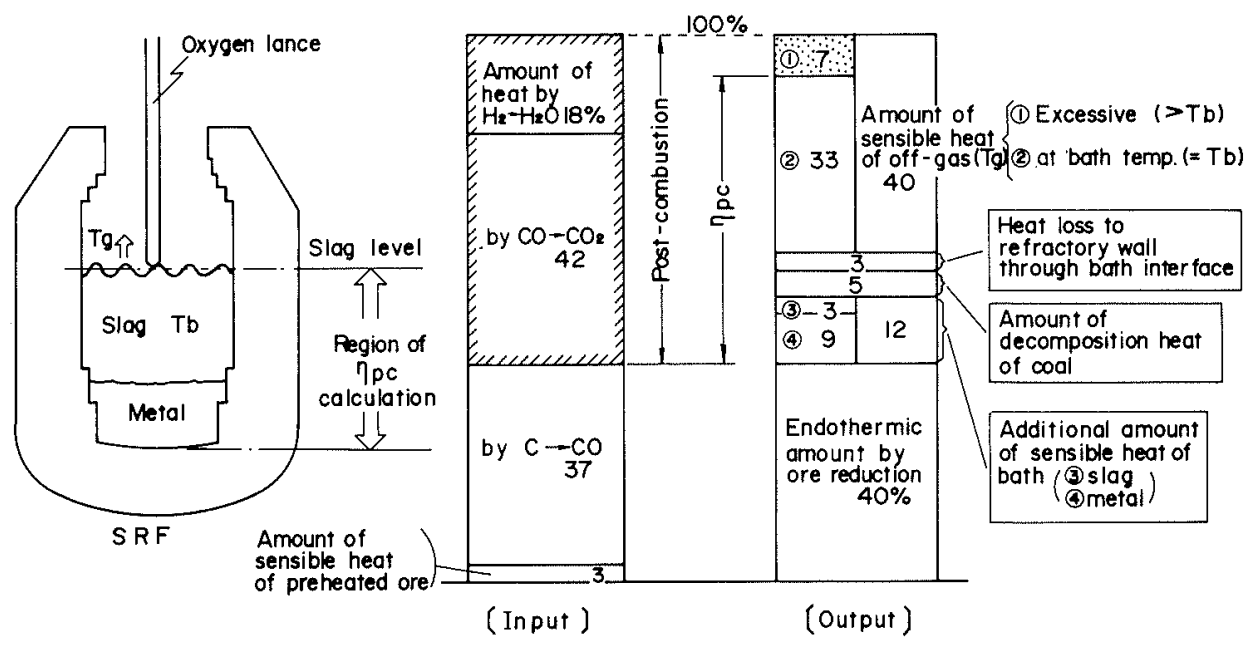

Fig. 18. Definition of heat transfer efficiency, $\eta_{\mathrm{PC}}$.

where, $\eta_{\mathrm{PC}}=100 \%$ in case the temperature of offgas above slag equals bath temperature.

In the case of Fig. $18, \eta_{\mathrm{PC}}=\{1-7 /(18+42)\} \times 100=$ $88 \%$.

\section{Appendix 2}

2.1. Carbon of volatile matter in coal at high temperature, $\mathrm{VMC}$, is expressed as follows;

$$
\mathrm{VMC}=\mathrm{T} . \mathrm{C} .-\mathrm{FC}^{\prime} \quad(\%)
$$

where, T.C.: Total carbon of coal obtained from proximate analysis $(\%)$

$\mathrm{FC}^{\prime}$ : Carbon content in $\mathrm{FC}^{*}(\%)$ $=\beta \cdot \mathrm{FC}^{*}(\%) \quad(\beta=0.97)$

FC*: Fixed carbon content in coal obtained at high temperature over $1200^{\circ} \mathrm{C}(\%)$ (dry base)

$$
=100-\left(\operatorname{ash}+\mathrm{VM}^{*}\right)(\%)
$$

VM*: Volatile matter generated from coal at high temperature over $1200^{\circ} \mathrm{C}$

$$
=\alpha \cdot \mathrm{VM}(\%)
$$

VM: Volatile matter obtained

from proximate analysis (\%) $\alpha=1.0$ at MV coal

1.18 at HVl coal

1.10 at HV2 coal

2.2. Definition of Fixed Carbon Combustion Ratio (FCR)

$\mathrm{FCR}=\frac{\left(\begin{array}{c}\text { Amount of combustion of fixed carbon } \\ \text { in coal per ton hot metal produced }\end{array}\right)}{\left(\begin{array}{c}\text { Amount of consumption of top blown } \\ \text { oxygen per ton hot metal produced }\end{array}\right)}=\frac{\omega_{\mathrm{FC}}}{\omega_{\mathrm{Ox}}}$,

$$
\mathrm{kg}-\mathrm{FC} / \mathrm{Nm}^{3}-\mathrm{O}_{2}
$$

where, $\omega_{\mathrm{FC}}=($ Amount of coal consumption $) \times \mathrm{FC}^{\prime} / 100$

$$
-\left(\begin{array}{l}
\text { Amount of carbon } \\
\text { consumed by reduction } \\
\text { and dissolution }
\end{array}\right), \mathrm{kg}-\mathrm{FC} / \mathrm{THM} .
$$

